\title{
CAMINHANDO JUNTO COM AS FAMÍLIAS DOS BEBÊS: narrativas da autobiografia docente
}

\author{
Eliene Santos de Faria Costal \\ Daniele Dorotéia Rocha da Silva de Lima²
}

\section{RESUMO}

O artigo, de caráter autobiográfico, aborda o processo de constituição e ressignificação do fazer docente de uma das autoras a respeito da relação com as famílias dos bebês em uma unidade de educação infantil pública do município de Belém, no estado do Pará. É um recorte da dissertação de mestrado intitulada "Docência com bebês? Autobiografia docente: por entre currículo e outras tramas", concluída no Programa de Pós-Graduação em Gestão e Currículo da Escola Básica - UFPA. Tem como objetivo apresentar considerações sobre o processo de construção da concepção sobre a relação docente-família enquanto especificidade da docência e da educação de bebês, refletindo sobre as experiências configuradas em meio aos entrelaçamentos das dimensões temporais, relacionais e institucionais das experiências formativas de uma das autoras, considerando as mudanças de concepções que influenciaram a ressignificação de conceitos e do seu fazer pedagógico. Para essa ação investigativa, optou-se pela pesquisa autobiográfica com método narrativo (CLANDININ e CONNELLY, 2011; JOSSO, 2010), como um percurso teórico-metodológico capaz de fundamentar o estudo e como potente ferramenta para a ressignificação das experiências vividas e transformação da práxis mediante o processo de formação e (auto)formação. A relação com as famílias é fundamental e indispensável para a educação de bebês em contexto de vida coletiva e uma das especificidades dessa docência, sendo possível considerar que a construção da concepção de docência, educação infantil e suas especificidades, é parte de um processual percurso formativo e constitutivo de docência, o qual na referida pesquisa, fez-se por meio das experiências em espaços, tempos e interações.

Palavras-chave: Autobiografia docente. Relação docente-família. Docência com bebês.

\footnotetext{
1 Mestre em Currículo e Gestão da Escola Básica pela Universidade Federal do Pará; Professora de educação infantil na Secretaria Municipal de Educação e Cultura SEMEC/Belém - PA; Técnica em educação na Secretaria de Estado de Educação SEDUC/PA. Orcid iD: https://orcid.org/0000-0002-8932-5455. E-mail: eliene.smile@gmail.com

2 Doutora em Educação em Ciências e Matemática pelo PPGECM/IEMCI/UFPA; Professora no Instituto de Ciências da Educação - ICED da Universidade Federal do Pará; É membro do grupo de pesquisa de formação de professores (TRANS) FORMAR, vinculado ao IEMCI/UFPA; Credenciada no Programa de Pós-Graduação em Currículo e Gestão da Escola Básica PPEB; Compõe o núcleo gestor do Grupo de Estudos e Pesquisas sobre Infâncias e Educação; É membro do Fórum de Alfabetização, Leitura e Escrita Flor do Grão Pará. Orcid iD: https://orcid.org/0000-0002-1790-9259. E-mail: danieledoroteia@gmail.com
} 


\title{
WALKING TOGETHER WITH THE FAMILIES OF BABIES: narratives of the teacher
}

\author{
autobiography
}

\begin{abstract}
The article, of an autobiographical character, addresses the process of constitution and reframing the teaching practice of one of the authors regarding the relationship with the babies' families in a public early childhood education unit in the municipality of Belém, in the state of Pará. Of the master's thesis entitled "Teaching with babies? Teaching autobiography: between curriculum and other plots "concluded in the Graduate Program in Management and Curriculum of the Basic School - UFPA. It aims to present considerations on the process of construction of the conception of the teacher-family relationship as a specific feature of teaching and baby education, reflecting on the experiences configured in the interplay of the temporal, relational and institutional dimensions of the formative experiences of one of the authors, considering the changes in conceptions that influenced the ( $\mathrm{re}$ ) meaning of concepts and their pedagogical practice. For this investigative action, we opted for autobiographical research with a narrative method (CLANDININ and CONNELLY, 2011 ; JOSSO, 2010), as a theoretical-methodological path capable of substantiating the study and as a powerful tool for the redefinition of lived experiences and transformation of praxis through the process of formation and (self) formation. The relationship with families is fundamental and indispensable for the education of babies in the context of collective life and one of the specificities of this teaching, and it is possible to consider that the construction of the concept of teaching, early childhood education and its specificities, is part of a procedural formative path and constitutive of teaching, which in that research, was done through experiences in spaces, times and interactions.
\end{abstract}

Keywords: Teaching autobiography. Teacher-family relationship. Teaching with babies.

\section{CAMINANDO JUNTO A LAS FAMILIAS DE LOS BEBÉS: narraciones de la autobiografía del maestro}

\section{RESUMEN}

El artículo, de carácter autobiográfico, aborda el proceso de constitución y replanteamiento de la práctica docente de uno de los autores sobre la relación con las familias de los bebés en una unidad pública de educación infantil del municipio de Belém, en el estado de Pará. De la tesis de maestría titulada "¿Enseñar con bebés? La autobiografía docente: entre currículum y otras tramas "concluyó en el Programa de Posgrado en Gestión y Currículo de la Escuela Básica - UFPA. Tiene como objetivo presentar consideraciones sobre el proceso de construcción de la concepción de la relación maestro-familia como rasgo específico de la enseñanza y la educación infantil, reflexionando sobre las vivencias configuradas en la interacción de las dimensiones temporal, relacional e institucional de las experiencias formativas de uno de los autores, considerando los cambios en las concepciones que influyeron en el (re) significado de los conceptos y su práctica pedagógica. Para esta acción investigativa se optó por la investigación 
autobiográfica con método narrativo (CLANDININ y CONNELLY, 2011; JOSSO, 2010), como un camino teórico-metodológico capaz de fundamentar la estudio y como herramienta poderosa para la redefinición de las experiencias vividas y la transformación de la praxis a través del proceso de formación y (auto) formación. La relación con las familias es fundamental e indispensable para la educación de los bebés en el contexto de la vida colectiva y una de las especificidades de esta enseñanza, y es posible considerar que la construcción del concepto de enseñanza, educación infantil y sus especificidades, es parte de un camino formativo procedimental y constitutivo de la docencia, que en esa investigación, se hizo a través de vivencias en espacios, tiempos e interacciones.

Palabras clave: Enseñanza de la autobiografía. Relación maestro-familia. Enseñar con bebés.

\section{INTRODUÇÃO}

O artigo sinaliza aspectos constitutivos da formação docente de uma das autoras no que diz respeito ao processo de construção da sua relação com as famílias dos bebês das turmas de berçários ao longo de treze anos de docência.

Considera a potencialidade reflexiva da pesquisa autobiográfica, a qual possibilitou a reflexão, compreensão, significação e ressignificação da sua docência com bebês por meio das narrativas, tendo por base as experiências - referência (JOSSO, 2004), as quais consistem nas experiências formadoras (JOSSO, 2004), que expressam comportamentos, pensamentos, saber-fazer, sentimentos, identidades e subjetividades.

Essa trajetória de constituição na docência com bebês é apresentada no estudo investigativo, por meio de episódios narrativos (SHULMAN, 1986), por considerarmos ser uma das formas de comunicar os saberes dos professores sobre a sua prática. Desta forma, o presente artigo versa sobre a reflexão e análise de um destes episódios, que é a relação com as famílias, enquanto ação fundamental da docência na educação infantil, em especial com os bebês, apresentando o processo gradativo de construção, por meio de experiências formativas, tanto da interação com as famílias no cotidiano da creche, quanto aos conhecimentos pela via do estudo, numa relação dialética entre teoria e prática.

A relação com as famílias configura-se pelo compartilhar do cuidado e educação das crianças pequenas, o que envolve dentre outras questões, 
parceria, confiança, respeito, escuta e organização de forma a possibilitar oportunidades de participação destas na creche. Quando se trata da educação de bebês, o processo de construção das relações é bastante delicado, pois o fato de serem tão pequenos, os pais e demais responsáveis, tendem a estar mais inseguros e preocupados, especialmente no momento de inserção destes no ambiente da creche, uma vez que este é o início da construção dos laços de afetividade e confiança com os docentes e a instituição.

Barbosa (2010), ressalta que a construção de uma boa relação com as famílias é responsabilidade dos docentes e dos gestores da creche, na qual os encontros e a participação das famílias podem ser realizados de diversas formas, de modo individual ou coletivo, o que contribui para trocas e escutas, favorecendo os laços de afeto e confiança, sendo o que essencialmente irá facilitar o estabelecimento de vínculos seguros ao bebê.

Nesse sentido, o texto fundamenta-se teoricamente a partir das contribuições de autores que tratam da pesquisa autobiográfica, formação de professores e educação infantil, tais como: Clandinin e Connelly (2011); Nóvoa (2013); Josso (1988, 2004, 2010); Passeggi e Barbosa (2008); Barbosa (2010) e Oliveira et al. (2011). Assim, a partir da compreenção da constituição da docência de uma das autoras, como processo de um percurso formativo, catalizador de concepções, mudanças e transformações da sua forma de ser e exercer a docência com bebês, o que inclui o fator indispensável ao desempenho da docência e educação de bebês, que é a relação com as famílias.

\section{A PESQUISA AUTOBIOGRÁFICA E OS MÉTODOS DA PESQUISA}

A pesquisa autobiográfica diz respeito ao movimento e ação em que o pesquisador é autor da narrativa escrita da própria vida, numa situação em que ocupa dois lugares concomitantes, o de pesquisador e 0 de pesquisado, constituindo-se em um movimento intencional de pesquisaformação (JOSSO, 2010). Deste modo a narrativa autobiográfica insere-se na: 
[...] tentativa de dar acesso a um percurso interior que evolui correlativamente (mesmo quando há desfasamentos temporais) para um percurso exterior caracterizado por acontecimentos, atividades, deslocamentos, relações contínuas e encontros, pertenças etc. É precisamente na exposição por meio da linguagem das componentes objetivas deste itinerário exterior que se exprime, implícita ou explicitamente, o olhar lançado sobre ele e as dimensões sensíveis que dão cor a essas vivências ou experiências (JOSSO, 2004, p. 186).

Nesse sentido, a pesquisa narrativa autobiográfica, caracteriza-se como um tipo de pesquisa biográfica, contribuindo para o que propõe o presente estudo, ao passo que o trabalho biográfico "faz parte do processo de formação; ele dá sentido, ajuda-nos a descobrir a origem daquilo que somos hoje" (JOSSO, 2010, p. 159).

A escrita autobiográfica, refere-se a "um exercício poderoso de metareflexão e, portanto, de tomada de consciência de quem somos nós em diferentes dimensões da nossa existência" (JOSSO, 2004, p. 173). Diz ainda a autora, que o movimento dessa escrita, torna-se um lugar de reflexão crítica sobre o próprio conhecimento, um novo espaço para a compreensão de si é aberto, como as passividades, as resistências, assim como as adesões às mudanças.

Dessa forma, o método de autobiografar-se, tem como característica e pretenção, "atribuir à subjetividade um valor de conhecimento" (FERRAROTTI, 1988), o qual segundo Larrosa (1994), é um movimento em que ocupamos ao mesmo tempo, o lugar de autores, narradores e personagens principais.

Assim, os caminhos teórico-metodológicos trilhados no estudo, foram subsidiados pela pesquisa narrativa autobiográfica, sendo utilizados, como instrumentos de pesquisa, disparadores de memória, por meio de diários e registros escritos, tais como planos de aula, projetos pedagógicos, escritos pessoais, e fotografias, que auxiliaram no processo do "caminhar para si" (JOSSO, 2010, p. 24). Segundo Josso (2010) o processo narrativo autobiográfico se configura em uma caminhada ao encontro de si, que provoca reflexões e autoconhecimento formador. 
A trajetória da constituição da docência com bebês nesta pesquisa, foi apresentada por meio de episódios narrativos (SHULMAN, 1986), considerada uma das formas de comunicar os saberes dos professores sobre a sua prática, alinhando-se às recordações-referência (JOSSO, 2004), as quais consistem nas experiências formadoras (JOSSO, 2004) que expressam comportamentos, pensamentos, saber-fazer, sentimentos, identidades e subjetividades. Tais recordações-referência foram acionadas pelos momentos charneira (JOSSO, 1988), caracterizado por momentos marcantes na vida do sujeito, gerando rupturas, articulações e mudanças.

Desta forma, a organização de tais episódios narrativos foi realizada com base nas suas experiências num percurso de treze anos de docência com berçários, contribuindo assim para investigar e compreender os elementos que dão sentido e permeiam as narrativas autobiográficas com respeito à sua constituição de docente de bebês.

Nessa linha de pensamento, a inquietação investigativa seguiu, com base em Passeggi e Barbosa (2008), três níveis de pensar a experiência, no trabalho sobre a vida e o eu, quais sejam: "o da evocação sobre a formação, o da reflexão que produz conhecimento e o da interpretação que permite tirar as lições de vida e gerar aprendizagens" (PASSEGGl; BARBOSA, 2008, p. 55). Sobre esse caminhar, a autora ressalta ainda, a síntese dessas três grandes etapas, nas quais o pesquisador se põe a questionar sobre: que fatos marcaram a minha vida? - que diz respeito à busca sobre os fatos marcantes da vida, contribuidores para a compreensão sobre a formação. Na etapa seguinte, o questionamento sobre: o que esses fatos fizeram comigo? - contribui para a reflexão e construção da história, momento este que representa questionamento de valores, construção e reconstrução de conhecimentos. Posteriormente, ao questionar sobre: o que faço agora com o que isso me fez? - o pesquisador entra na fase da interpretação das aprendizagens e formação.

Ademais, buscou-se situar as experiências formadoras com base na teoria do espaço tridimensional (CLANDININ; CONNELLY, 2011). Segundo os autores, toda experiência se inscreve num espaço tridimensional, avocando 
as dimensões temporal, relacional e institucional, o que dizem respeito à interação entre presente, passado e futuro, a relação à nível pessoal e social, assim como ao lugar/lugares ou cenários em que ocorrem as experiências.

Nessa linha de pensamento, no processo metodológico que a pesquisa seguiu, as reflexões e, de certa forma, as análises, ocorreram concomitante à escrita das narrativas, pelo próprio caráter autobiográfico, que não permite dissociar a escrita da reflexão. Ademais, utilizou-se como método de análise para o material produzido e engendrado por meio dos episódios narrativos, o método de Análise Narrativa (BOLÍVAR, 2002), o qual perpassa pelo aspecto hermenêutico e analítico, analisando os sentidos que emanam da totalidade do processo que se reconhece e se toma como fatores formativos ao longo da trajetória docente.

Ressalta-se que no seguimento do texto do presente artigo, assume-se a escrita em primeira pessoa, por tratar-se de um episódio narrativo, seguindo os pressupostos da pesquisa autobiográfica.

\section{O PROCESSO DE CONSTRUÇÃO DA QUALIDADE NAS RELAÇÕES COM AS FAMÍLIAS DOS BEBÊS: NARRATIVAS DA CONSTITUIÇÃO DOCENTE}

Ao longo dos treze anos como professora de berçário, aprendi que construir parceria com os pais dos bebês é o único caminho viável para conseguir garantir uma educação de qualidade para os pequeninos.

Todavia, construir um relacionamento de confiança e parceria com as famílias não é uma tarefa fácil. Ao contrário, é delicada e gradativa, além de tratar da educação de crianças tão pequenas, muitas vezes, o que o professor pode levar dias e meses para construir uma relação de confiança com os pais, às vezes, pequenas situações podem levar minutos para se desconstruir laços que pareciam formados. Isso ocorre facilmente, caso não haja investimento nessa relação desde o primeiro contato entre professores, bebês e seus responsáveis no ambiente da creche.

Lima (2015) reconhece a importância da presença da família na sua diversidade e pluralidade e nos ajuda a refletir que junto a esta podemos 
concentrar esforços no sentido de projetar intenções que podem influenciar na formação do sujeito, evidenciando que "a família é um território onde se pode observar influências formativas que ultrapassam espaços e tempos" (LIMA, 2015, p. 59).

Ao pensar na importância da relação com as famílias, recordo-me do meu início como professora, no qual durante anos, no período de matrícula das crianças na UEl eram realizadas visitas pelas professoras às casas de todas as crianças que faziam a chamada "pré-matrícula", uma vez que as vagas disponíveis eram insuficientes à quantidade de procura e necessidade da comunidade local.

Nesse momento era possível conhecer um pouco da realidade das crianças que iriam adentrar à creche e de suas famílias. Confesso que a precariedade e a extrema pobreza faziam destes dias um momento triste que marcam a minha docência de certa forma, pois levava não somente a mim, mas às demais professoras, a uma profunda reflexão que iria para além do profissional. Recordo terminar o turno com uma carga emocional muito pesada, haja vista que ficava em nossas mãos a sentença de quem iria conseguir a vaga e quem ficaria de fora. Diante das situações que presenciávamos, a educação e o desenvolvimento das crianças não eram os únicos fatores que a matrícula na creche poderia oferecer e representar na vida dos bebês.

Nesse cenário, rememoro e narro essa experiência percebendo em que contexto o respeito pelas famílias dos bebês criou raiz profunda dentro de mim. Todavia, importa ressaltar, que tal reflexão está distante da ideia de que o meu respeito às famílias depende da sua condição econômica e social, por pena ou outras questões. Só lembro desse início e sinto, e como sinto!

Acompanhando as narrativas, essa experiência inicial me toca e provoca a reflexão sobre questões de cunho político e social, uma vez que nesse período de 2006, momento em que iniciei o estágio, até meados de 2014, o método de seleção para a matrícula no município era realizado da mesma forma, uma dura realidade da natureza seletiva. Sentíamos que as 
famílias mesmo em situação de extrema pobreza, demonstrando intenção e necessidade da vaga para seus filhos na creche, tentavam esconder, ou justificar a posse de fogão, geladeira, aparelho de televisão, entre outras questões básicas da vida, como se fossem parâmetros para perderem a vaga para outras famílias mais pobres.

Direitos relegados! Tanto no que tange à educação pública às crianças, conforme a Constituição/1988, O Estatuto da Criança e do Adolescente/1990 e Lei de Diretrizes e Bases da Educação - Lei n 9.394/1996, quanto ao conhecimento e consciência de que a educação pública se trata de um direito que precisa ser garantido e não um favor a ser prestado.

Tal situação ocorria, em virtude da insuficiência de vagas e creches para atender a demanda de crianças e famílias que precisavam desse serviço, demonstrando a falta de planejamento, investimento e valorização do poder público para a educação no país, que embora com pequenos avanços, a alta demanda de crianças fora da creche e a pouca oferta ainda persiste nos dias atuais.

De acordo com o Instituto Brasileiro de Geografia e Estatística (IBGE)/2018, por meio dos dados da Pesquisa Nacional por Amostra de Domicílios Contínua (PNAD)/2016-2017, as crianças de zero a três anos, num percentual de $21,1 \%$ dos bebês de zero a um ano e $34,7 \%$ das crianças de dois e três anos, estavam fora da escola em virtude da inexistência de vagas ou de creches próximas às suas residências. Ainda segundo estes dados, a Região Norte foi a que apresentou menor taxa de escolarização entre as crianças de até três anos (16,9\%).

Atualmente, a pré-matrícula é realizada no município de Belém, por meio de inscrições online, não há mais visitas, mas os direitos continuam sendo relegados a meu ver. Ao passo que nem a internet, nem a vaga na creche, constituem-se como fatores acessíveis à todas as famílias que apresentam interesse em matricular seus filhos, principalmente as de baixa renda.

Nesse viés, corroborando com a reflexão acima, que fala sobre a minha história individual, a qual também constitui uma interação social, 
trazendo um recorte de um momento e um contexto social e político em que vivi tais experiências, Ferrarotti (1988) ressalta sobre o cunho sociológico das biografias, não se tratando apenas de uma simples narrativa a contar sobre as experiências vividas individualmente, mas trata-se também de uma micro relação social. E, portanto, acaba por tornar-se um instrumento sociológico que pode servir de mediação entre a história individual e a história social.

Considerando esse momento da minha experiência com as famílias ao longo do meu percurso formativo, proponho-me a mudar um pouco de viés, reportando-me ao processo de construção de relacionamento com estas, que envolve mais uma trama entre tempos, espaços e interações.

Inicio ressaltando a relevância da criação de vínculos de segurança e afetividade com as famílias dos bebês para de fato garantir uma educação que possa contribuir para a formação humana de forma saudável a estes.

Destarte, desde que iniciei o trabalho como professora na educação infantil, observo que as relações entre famílias e professores é uma relação delicada que requer muitos cuidados, por tratar-se de um momento em que as famílias tendem a estar fragilizadas, com sentimentos de remorso e culpa, por precisarem deixar seus bebês, ainda pequenos e frágeis, aos cuidados de estranhos em um ambiente coletivo como a creche.

Nesse sentido, trago narrativas individuais, mas que evidenciam também ações vivenciadas em coletivo, experiências com as famílias e com as professoras das turmas de berçário com as quais trabalhei.

Assim sendo, recordo de um momento que representou uma grande mudança quanto ao relacionamento com as famílias dos bebês e das crianças maiores, não só com relação a mim, mas envolvendo o corpo docente e gestor da UEl de forma geral. Refiro-me às ações propostas por uma pesquisa-formação de professoras ${ }^{3}$ da UFPA no ano de 2013. Tal ação

\footnotetext{
3 Professora Dra. Celi da Costa Silva Bahia, docente do Curso de Pedagogia do Instituto de Ciências da Educação da UFPA. Coordenadora geral do Grupo de Estudos e Pesquisa em Educação Infantil (IPE) e diretora da Faculdade de Educação/ICED/UFPA; Professora Dra. Solange Mochiutti, aposentada da Escola de Aplicação da Universidade Federal do Pará
} 
foi desenvolvida com uma turma de berçário da unidade, porém não era a que eu trabalhava. Contudo, à medida em que observávamos que as mudanças de certas situações, tornavam-se significativas na turma de destino da pesquisa, acrescentávamos também uma postura semelhante à nossa prática, principalmente as que diziam respeito à relação com as famílias dos bebês.

Dessas mudanças, as principais estavam voltadas à ação de maior contato com as famílias, especialmente nos momentos de entrada e saída dos bebês. A partir desta observação e da relação com as professoras da turma, anteriormente à pesquisa, esse contato limitava-se ao "recebimento" e "entrega" dos bebês na porta da sala, o que tornavam as falas restritas ao repasse de informações, e as conversas, quando possíveis, eram em cunho de cobrança de ambos os lados, professoras e famílias.

Ao focalizar esse processo, na UEl, tem-se o costume de preservar uma pequena cancela na porta da sala dos berçários, em virtude da necessidade de deixá-la aberta, pela pouca ventilação do ambiente, como também pela proximidade com o banheiro, representando um risco para os bebês. Acontece que na entrada e saída dos bebês, essa cancela tornavase uma limitação e uma barreira simbólica, um "muro" entre os pais e as professoras.

Passamos então a abrir essa cancela e incentivar que os pais adentrassem na sala, estando livres para sentarem-se com seus bebês e as mães que amamentavam pudessem ficar à vontade em amamentar seus filhos. E assim, com o maior tempo de permanência dos pais na sala do berçário, os momentos de conversas entre nós professoras e famílias foram se ampliando, possibilitando a construção de vínculos afetivos e a troca recíproca sobre a educação e desenvolvimento dos bebês da turma.

Segundo as professoras realizadoras da pesquisa, Bahia e Mochiutti (2017), a cadeia formativa propiciada pela pesquisa-formação, quando

(EA-UFPA). Integra o Grupo de Estudos e Pesquisas em Educação Infantil (IPE) do Instituto de Educação (ICED/UFPA). 
potencializada pelas rodas de conversa e debates de situações vivenciadas pelas professoras e bebês no cotidiano da creche, considerava as necessidades formativas levantadas pelas professoras, permitindo a reflexão e articulação de saberes, num processo de formação continuada, de forma a proporcionar maior tranquilidade e segurança às professoras quanto ao fazer docente junto aos pequeninos.

Neste contexto, considero que as mudanças foram propostas partidas da então pesquisa-formação para a turma em que esta foi desenvolvida. Contudo, alcançou as demais turmas e o espaço educativo como um todo, sendo mudanças significativas capazes de ressignificar nosso contexto.

Assim, sigo refletindo sobre as experiências que deixaram marcas, que foram capazes de ir moldando a construção da minha docência, ampliando a minha possibilidade do fazer docente junto aos bebês. Deste modo, reporto-me às contribuições de Bragança (2008, p. 81), o qual afirma:

A narração das histórias de vida vem com o movimento propriamente humano de contar histórias e ressignificar experiências do passado que vão se desdobrando em projetos de futuro. No caso da formação docente, ao narrar o passado, vemos surgir uma versão sobre nós mesmos, os encontros e desencontros com a profissão e, ainda, as imagens da docência entranhadas no imaginário coletivo e individual.

Essa experiência com as famílias daquele momento, levou-me à ressignificação do meu fazer docente, projetando ações e encaminhamentos futuros na profissão, construindo um currículo significativo, vivo, que contribua com o desenvolvimento e humanização dos bebês.

Cabe pontuar, entretanto, com relação à construção de relacionamento com as famílias, que cada ano que se inicia uma turma de berçário, é um novo recomeço, os primeiros dias e meses são de estreitamento de laços de afetividade e segurança, não só para os bebês, mas também para suas famílias.

Confesso que para mim enquanto professora este é o momento mais difícil e mais cansativo do ano letivo em uma turma de berçário, o que chamamos na SEMEC/Belém, de momento de inserção e acolhida, o qual 
diz respeito ao processo de inserção dos bebês e crianças pequenas na UEl. E não poderia falar do relacionamento com as famílias sem falar sobre esse momento tão delicado e tão decisivo em todos os sentidos do trabalho, o qual será desenvolvido ao longo do período letivo.

Costumo dizer que tudo começa aí, bem nos primeiros dias da entrada dos bebês e suas famílias na UEl, haja vista que os laços de confiança e afetividade, são construídos neste momento e se não houver uma boa acolhida, tanto para os bebês, como para suas famílias, as relações serão fragilizadas. Os pais inseguros transmitirão para os bebês essa insegurança, que possivelmente terão mais dificuldade no processo de inserção.

Nesse sentido, a "quebra do muro" também foi essencial para esse momento de acolhimento, ao passo que a cultura que se criou de abertura para a presença das famílias no espaço da unidade, foi propulsora de um pensar diferenciado para o momento de inserção das crianças na creche, onde passamos a organizar esse período inicial dos bebês e suas famílias de forma que estas permaneçam o tempo necessário no ambiente da UEI, com o objetivo de construção de laços de afetividade, segurança e confiança, os quais entendo que serão melhor realizados por meio desse contato intenso na fase inicial do ano letivo dos pais, bebês e professoras.

Observamos que essa é a grande oportunidade das famílias conhecerem tanto as professoras, quanto o trabalho desenvolvido no berçário, a dinâmica, a rotina, as dificuldades em se trabalhar com um coletivo de bebês no espaço educacional de tempo integral.

Nesse ponto entra a reflexão sobre o momento de acolhimento e como este é decisivo para o trabalho desenvolvido no decorrer do ano, pois os vários anos de docência com berçário, a experiência com as mudanças de posturas e relação com as famílias, me levaram a observar que os pais que passam mais tempo conosco no período de inserção dos bebês se tornam os maiores parceiros e participativos na UEl, compartilham mais a educação dos seus filhos, assim como são mais sensíveis e compreensíveis no caso das intercorrências próprias de berçário, tais como mordidas, entre 
outras situações que podem vir acontecer com os bebês no ambiente da creche.

Em consonância a essa questão, Oliveira et al. (2011, p. 140) bem pontuam:

O bom relacionamento entre professores, demais educadores e famílias, processo a ser constantemente conquistado, contribui muito para o trabalho com as crianças, pois dificuldades surgidas podem se resolver mais rapidamente e a segurança é maior nas decisões que são tomadas em relação a elas. Cuidados com esta relação podem prevenir alguns problemas que costumam surgir.

Dessa forma, atribuo à fase da inserção dos bebês e suas famílias na creche como o alicerce da construção da relação de confiança, respeito e parceria. Isso ocorre porque nesse momento do ano as famílias tendem a compartilhar muitas vezes um turno inteiro ao lado das professoras, na delicada tarefa de acolher os bebês, alimentando, higienizando, confortando-os, cantando, dando colo para um, para dois, até para mais bebês ao mesmo tempo.

Mesmo após o processo de inserção dos bebês, a continuidade desse trabalho é indispensável. Dando liberdade às famílias a entrarem com seu bebê no início da manhã na sala de referência, poder compartilhar por meio do diálogo direto com as professoras, como o seu bebê passou a noite, sobre o desenvolvimento, educação e cuidado deste, ainda que de forma breve, porém diária.

Esse é um exemplo de uma experiência resultante de experiências anteriores, que se mantém num ciclo crescente, Clandinin e Connelly (2011) ajudam-me a refletir sobre um critério da experiência, que é a continuidade, que diz respeito a um processo em que uma experiência se desenvolve por meio de outra que a antecede e, prospectivamente dará lugar às outras, numa relação temporal entre presente, passado e futuro continuamente.

Assim, por meio da continuidade das experiências, o respeito e a parceria foram se construindo. Observo ademais, que o maior contato, vivência e diálogo, propiciam conhecimentos que entre outras questões, ampliam a informação, sensibilização e a possível conscientização das 
famílias do quanto é difícil o trabalho com um coletivo de bebês, onde muitas coisas, inclusive incidentes, podem acontecer, sem se tratar de irresponsabilidade e falta de cuidado das professoras para com os bebês.

Caminhar junto forma confiança, só se confia no que se conhece! Daí a grande importância do contato maior com as famílias, pois conflitos mediante questões pequenas, podem ser facilmente evitados. As relações abrandadas e parcerias possibilitam $\mathrm{o}$ bom andamento do trabalho no berçário. As conversas são mais leves e francas e o trabalho pedagógico com os bebês flui.

Nesse contexto, levada pela curiosidade investigativa de pesquisadora, me permiti buscar nos meus antigos cadernos de registros fatos sobre as intercorrências nas turmas de berçário, observei que as mordidas e demais incidentes, dentro da normalidade, sempre ocorreram, com algumas pequenas diferenças de uma turma para outra, creio que em virtude das suas especificidades.

Nos cadernos, não há registros sobre a postura dos pais diante da informação das professoras sobre os incidentes, mas a leitura destes registros escritos ajudou-me a revisitar expressões de sentimentos e a rememorar sobre fatos decorrentes. Recordo do quanto em algumas situações foi/é delicado ser professora do turno da tarde, uma vez que se trata de um período de saída dos bebês e, portanto, a professora da tarde acaba por se tornar a porta voz dos ocorridos ao longo do dia com os bebês.

Nessa linha de pensamento, refletindo sobre os primeiros anos e os dias atuais, posso afirmar, que conflitos com os pais sempre existiram e continuarão a existir. Todavia, a forma de resolvê-los, a sua intensidade e a postura das professoras e, consequentemente dos pais, foram os fatores que mudaram. Isto só foi possível porque as experiências vivenciadas foram propulsoras de formação e mudança de fazeres docentes, conferindo maior capacitação às professoras. Sobre essa questão, Oliveira et al. (2011), contribuem à reflexão ressaltando quanto a importância do preparo de ambas as partes, docentes e famílias, conforme o seguinte: 
Sendo assim, uma creche que pretenda aumentar a participação das famílias com parte do planejamento e realização das suas ações, necessita preparar tantos os seus profissionais, quanto as famílias para que aquela participação não implique prejuízos da qualidade do atendimento e consequentemente insucesso dessa iniciativa (OLIVEIRA et al., 2011, p. 137).

Dessa forma, considero que a construção de um bom relacionamento com as famílias perpassa por fatores complexos e da mesma forma especiais, como o compartilhamento da educação e do cuidado com os bebês ao longo do ano letivo e todo o período de permanência destes na instituição. Onde, conhecer e distinguir os papéis, direitos e deveres de cada um é imprescindível para evitar desconfortos, equívocos e conflitos, bem como para o desenvolvimento e bem-estar das crianças, as quais devem ser o centro de toda e qualquer ação promovida na instituição, e isto só é possível pela via do diálogo, processo das interações tão necessárias a esse tempo da infância. Conforme destaca Oliveira et al. (2011, p. 138):

Isso implica compartilhar os sucessos e as dificuldades que se apresentam e, acima de tudo, transformar este trabalho em colaboração mútua. Sem dúvida, há que se determinar o que deve ser responsabilidade da creche e o que deve ser da família. Mas os papéis de cada um só vão se construindo a partir do exercício cotidiano de dialogar.

O trabalho de colaboração mútua requer para além do compartilhamento de ações envolvendo a educação dos bebês, um olhar diferenciado que se torna possível a partir de uma postura de se colocar no lugar do outro, de escuta, de amorosidade e disposição.

Dowbor (2008) fala sobre a ocupação com o outro e sobre o quanto ocupar-se com o outro também depende da ocupação consigo próprio, por se tratar de uma ação necessária para o aprendizado da construção de um espaço, que é interno, de forma a permitir que a escuta do outro tenha um lugar dentro de nós. "Escutar o outro, portanto, significa ser capaz de trocar de lugar com ele" (DOWBOR, 2008, p. 68).

Na educação infantil trabalhar com as famílias se torna útil o exercício de ocupar-se com estas, criar um espaço em nós, docentes, para a escuta 
do que diz suas falas, seus gestos, seus corpos. Ocupar-se de suas histórias, de seus desejos e seus medos, para compreendê-los, para criar pontes de acesso a diálogos, compreensões e ajustes, quando necessário, o que contribui com o desenvolvimento e aprendizagem dos bebês.

Criar espaços para o outro em nós não é fácil, porém necessário! Recordo do momento em que consegui de uma forma mais tranquila, criar espaço para uma escuta mais sensível das famílias, para a compreensão da dimensão de sentimentos constantemente demonstrados por elas, como: insegurança, tristeza diante de uma mordida, de um machucado, da dificuldade na despedida nos primeiros dias de inserção na creche. Neste processo de mudanças conceituais e atitudinais, foi o momento em que mais me ocupei de mim mesma e do outro, o momento mais íntimo, profundo e poderoso da minha existência, a maternidade!

O início da minha docência antecedeu essa fase da minha vida pessoal. Assim, não podemos desconsiderar que fatos da vida pessoal se intercruzam com a profissional, e no meu caso, a maternidade atravessou da forma mais linda a minha vida por completo, inclusive a minha docência. Coadunando com as ideias de Nóvoa (2013), ao afirmar que a separação do profissional e do pessoal é impossível, ao passo que uma questão influencia na outra, onde as formas de ser e ensinar se cruzam e se desvendam.

Ser mãe me proporcionou experimentar sentimentos que me possibilitaram realizar identificações com as famílias, a compreender melhor o sentimento de medo, insegurança e tristeza apresentada por elas, criar espaços em mim para a escuta do outro. Assim, me aproximou e contribuiu para compreendê-los de uma forma mais genuína, num movimento de poder colocar-me no lugar destes diante das situações ocorridas.

Não se trata, porém, de considerar que ser mãe seja um requisito docente para ter um bom relacionamento com as famílias. Conforme apresentado anteriormente, a relação deve ser construída e fortalecida em todos os momentos da ação de educar bebês. Trata-se, portanto, de incursões subjetivas sobre fatos que de alguma forma tocaram e mudaram 
em algum requisito o meu olhar e o meu fazer docente, e nesse caso, para mim foi significativo esse processo de minha constituição docente.

Nesse sentido, a partir de várias experiências que possibilitaram uma mudança significativa no meu relacionamento com as famílias, contribuindo para mudanças de práticas, bem como mudança de concepções, considero que tais momentos na minha constituição enquanto professora de bebês, fez parte do meu processo formativo, como momentos que me marcaram e transformaram a minha forma de pensar e exercer a educação com crianças tão pequenas.

\section{CONSIDERAÇÕES FINAIS}

No emaranhado de situações, experiências, relações e contextos, foi sendo formada e constituída a docência com bebês de uma das pesquisadoras. Larrosa (2002) ressalta que experiência é aquilo que acontece atravessando-nos, é o que nos passa e nos transforma de algum modo, coadunando com a perspectiva das experiências formativas de Josso (2010), a partir do que considera momentos charneira, por serem acontecimentos potentes e marcantes, capazes de promover mudanças e transformações na forma de ser e exercer a docência.

Aponta-se reflexões acerca dos momentos charneira da pesquisadora com as famílias dos bebês e a forma como esta foi percebendo no cotidiano das interações, o quão relevante é a relação próxima do docente de bebês com as famílias e responsáveis destes, para que seja viável uma educação de qualidade que atenda às especificidades dos bebês, possibilitando o seu desenvolvimento saudável em todos os aspectos, em especial o emocional e afetivo, compreendendo que a boa relação com os pais tem ligação com o bem estar dos bebês e a construção segura de vínculos afetivos com os docentes.

Pôde-se perceber, que o seu percurso formativo também proporcionou à docente primar pelo respeito e valorização da história e família dos bebês, por compreender que esta é uma docência em que a 
educação precisa ser compartilhada. Zelar pela boa relação com as famílias propicia a parceria, a resolução tranquila e equilibrada de possíveis conflitos, bem como o encaminhamento da educação dos bebês de forma significativa.

Escutar, falar, orientar, saber o momento de calar ou a melhor forma de abordar assuntos e questões mais delicadas com as famílias dos bebês, requer saberes articulados com a compreensão do papel da docência e das singularidades que constituem a educação dos pequeninos, sendo este um exercício cotidiano de articulação consciente e inconsciente entre a teoria e prática da pesquisadora no seu percurso de formação.

Por meio da potencialidade da escrita e investigação narrativa autobiográfica, a autora da pesquisa, pôde compreender os sentidos das suas experiências, rememorando e refletindo sobre estas. Tais experiências, seja por meio de uma ação significativamente positiva ou mesmo das consideradas equivocadas, foram catalisadoras de aprendizagens e formação do seu fazer docente junto aos bebês e suas famílias.

Nessa toada reflexiva, considera-se que as aprendizagens e elementos formadores apresentados, revelam o quanto o conhecimento mediante estudos, pesquisas e demais ações formativas são relevantes para as aprendizagens sobre a educação, docência e suas especificidades, tornando-se referenciais teóricos capazes de criar bases e pontes para modificações e novas formas de caminhar, aliados ao saber da experiência de vida profissional. Estes são aspectos da docência da pesquisadora, resultado da confluência de muitos saberes, de muitas vozes e muitos espaços, os quais the conferem investimentos no continuum de novas experiências formadoras da docência com bebês, bem como na luta por uma educação pública de qualidade desde a mais tenra idade.

\section{REFERÊNCIAS}

ALVES, N. Nós somos o que contamos: a narrativa de si como prática de formação. In: SOUZA, E. C.; MIGNOT, A. Histórias de vida e formação de professores. Rio de Janeiro: Quartet, FAPERJ, 2008, p. 131-145. 
BAHIA, C. C. S.; MOCHIUTTI, S. Natureza e sociedade: contribuições da pesquisa-formação na construção de saberes e fazeres no berçário. Revista Cocar, v. 11, n. 21, p. 279-301, jan./jul. 2017. Disponível em:

<https://periodicos.uepa.br/index.php/cocar/article/download/1292/810>. Acesso em: 20 de out. de 2019.

BARBOSA, M. C. As especificidades da ação pedagógica com os bebês. In: Anais eletrônicos do I Seminário Nacional Currículo em movimento -

Perspectivas atuais. Belo Horizonte, 2010. Disponível em:

<http://portal.mec.gov.br/docman/dezembro-2010-pdf/7154-2-2-artigo-mecaçao-pedagogica-bebes-m-carmem/file>. Acesso em: 30 de set. de 2020.

BOLÍVAR, A. B. 'De nobis ipsis silemus?': Epstemoligia de la investigación biográfico-narrativa em educación. Revista Eletrónica de Investigacion Educativa, vol. 11, n. 1. Barcelona, 2002. Disponível em:

<http://redie.ens.uabc.mx/vol4n01/contenido-.html>. Acesso em: 20 de jul. de 2019.

BRAGANÇA, I. F. S. Histórias de vida e formação de professores/as: um olhar dirigido à literatura educacional. In: SOUZA, E. C. de; MIGNOT, A. Histórias de vida e formação de professores. Rio de Janeiro: Quartet, FAPERJ, 2008, p. 65 88.

BRASIL. Constituição da República Federativa do Brasil, de 05 de dezembro de 1988. Brasília, 1988.

BRASIL. Estatuto da Criança e do Adolescente. Lei Federal n. 8069, de 13 de julho de 1990. Brasília, 1990.

BRASIL. Lei de Diretrizes e Bases da Educação Nacional. Lei n. 9394, de 20 de dezembro de 1996. Brasília, 1996.

CLANDININ, D. J.; CONNELLY, F. M. Pesquisa narrativa: experiência e história da pesquisa qualitativa. Tradução: Grupo de Pesquisa Narrativa e Educação de Professores, UFU. Uberlândia: EDUFU, 2011.

DOWBOR, F. F. Quem educa marca o corpo do outro. - 2. ed. São Paulo: Cortez, 2008.

FERRAROTTI, F. Sobre a autonomia do método biográfico. In: NOVOA, A.; FINGER, M. (Orgs.). O método (auto) biográfico e a formação. Lisboa: Ministério da Saúde, 1988, p. 18 - 34.

IBGE - Instituto Brasileiro de Geografia e Estatística. Pesquisa Nacional por Amostra de Domicílios Contínua (PNAD- contínua) 2018. Brasília, IBGE, 2018. 
JOSSO, M. C. Da formação do sujeito... ao sujeito da formação. In: NOVOA, A.; FINGER, M. (Orgs). O método (auto) biográfico e a formação. Lisboa: Ministério da saúde, 1988, p. 35 - 50.

JOSSO, M. C. Experiências de vida e formação. Lisboa: Educa, 2002.

JOSSO, M. C. Experiências de vida e formação. Tradução José Claudinho e Júlia Ferreira. São Paulo: Cortez, 2004.

JOSSO, M. C. Experiência de vida e formação. - 2. Ed. Ver. e. ampl. Natal, RN: EDUFRN; São Paulo: Paulus, 2010.

LARROSA, J. Tecnologias do Eu e Educação. In: SILVA, T. T. (org.). O sujeito da Educação: estudos foucautianos. Petrópolis, RJ; Vozes, 1994. p. 35 - 86.

LARROSA, J. Notas sobre experiência e o saber da experiência. Revista Brasileira de Educação. N. 19, p. 20- 28. [ s. m.], jan./ fev./ mar./ abr. 2002. <http://www.scielo.br/pdf/rbedu/n19/n19a02.pdf>. Acesso em: 14 de nov. de 2018.

LIMA, D. D. R. S. Clube de Ciências da UFPA e docência: experiências formativas desde a infância. Tese (Doutorado) - Universidade Federal do Pará. Programa de Pós-graduação em Educação em Ciências e Matemáticas, Belém, 2015.

NÓVOA, A. (Org.). Vidas de professores. $2^{a}$ ed. Porto: Porto Editora, 2013. p. $11-30$.

OLIVEIRA, Z. et al. Creches, crianças, faz-de-conta \& Cia.16. Ed. AtualizadaPetrópolis, RJ: Vozes, 2011.

PASSEGGI, M. da C.; BARBOSA, T. M. N. (Org.). Memórias, memoriais: pesquisa e formação docente. - Natal, RN: EDUFRN; São Paulo: Paulus, 2008. 286p. (Coleção Pesquisa (Auto) Biográfica - Educação).

SHULMAN, L. S. Knouledge and Teaching: Foundationsof The. New Reform. Harvard Educational Rexarcher, [s. I.], v. 15, n. 2, p. 4 - 14, feb. 1986.

Recebido em: 12 de setembro de 2021. Aprovado em: 20 de dezembro de 2021. Publicado em: 07 de janeiro de 2022. 